Open Access

\title{
A model of rhetorical markers competence in writing academic research articles: a qualitative meta-synthesis
}

\author{
Reza Khany ${ }^{1}$, Mohammad Aliakbari $^{2}$ and Saeedeh Mohammadi ${ }^{*}$
}

* Correspondence: S.Mohammadi.
TEFL@gmail.com
'English Department of llam
University, llam, Iran
Full list of author information is
available at the end of the article

Springer Open

\begin{abstract}
The knowledge of diverse rhetorical relations is a remarkable component of competence in research article (RA) writing for learners' successful handling of scholarly writing tasks in English for academic purposes (EAP) programs. This study aimed to present a model of Rhetorical Markers (RMs) competence in writing EAP RAs. In so doing, a 'qualitative meta-synthesis' approach was adopted as the research method. A meta-synthesis exercise was framed and the currently available literature on various models of RMs was investigated. 385 relevant abstracts and 321 full papers were screened and a number of 23 studies were appraised for final inclusion. Afterwards, a reciprocal translation was conducted to extract the latent themes and concepts in the general model. More specifically, a thematic coding strategy was applied for synthesizing the selected studies. Then, different obtained themes and categories were synthesized to build the major components of the model of RMs competence. Finally, three super themes of RMs were emerged including: pragmatic markers, meta-discourse markers, and metaphorical markers. The new model, as a conceptual frame of reference, can provide awareness to the EAP researchers regarding the underpinning components of the knowledge of RMs in writing up academic research papers.
\end{abstract}

Keywords: Rhetorical markers, English for academic purposes, Research article, Research article writing competence, Meta-synthesis

\section{Introduction}

Research articles (RAs) are acknowledged as the most important form of scientific discourse because they are leading means of distributing academic knowledge for future use. Over the recent decades, the study of RAs has received much attention in the academic genre analysis. A variety of perspectives has been put under deep consideration, including organization, lexicon, cohesion and coherence markers, rhetorical moves, etc. (e.g., Hyland \& Tse, 2005; Khany \& Tazik, 2010; Li \& Ge, 2009; Luo \& Hyland, 2016; Swales, 2004).

Among the significant linguistic features explored in the literature on text analysis are cohesion and coherence markers (e.g., Anderson, 2001; Bolden, 2009; Fraser, 2005; Goatly, 1997). Coherence and cohesion are captured by a set of rhetorical markers (RMs), which represent the explicit and implicit relations between different discursive segments and manage the flow of discourse. An explicit relation is marked by an

(c) The Author(s). 2019 Open Access This article is distributed under the terms of the Creative Commons Attribution 4.0 International License (http://creativecommons.org/licenses/by/4.0/), which permits unrestricted use, distribution, and reproduction in any medium, provided you give appropriate credit to the original author(s) and the source, provide a link to the Creative Commons license, and indicate if changes were made. 
explicit connective, but in an implicit one, the connective is absent, and it is difficult to recognize the discourse relation (Pitler et al., 2008). It is worth noting that the concepts contributing to coherence relations and their discourse markers highly draw upon the prominent linguistic theory of Halliday's (1994) systemic functional linguistics. His theory suggests that an intended meaning is postulated for any kind of verbalization leading to the readability of the text. As such, discourse connectives are utilized to represent a type of rhetorical relation and make the interpretation of the text possible. These concepts also fundamentally contribute to Rhetorical Structure Theory (Mann \& Thompson, 1988), which accounts for the connections between distinct units of the text and the functions each connection serves in the text. The knowledge of these markers is of high necessity in producing a well-organized research article in English. Given this, several models have been also proposed by different scholars: Goatly's (1997) model of metaphorical markers (MMs), Fraser's (2005) model of discourse markers (DMs), Hyland's (2005) model of Metadiscourse Markers (MDMs), and Fraser's (2009) model of Pragmatic Markers (PMs). A detailed review of current literature on different sets of rhetorical markers is provided as follows.

\section{Literature review}

Rhetorical organization in writing is manifested through some linguistic and meta-linguistic cues called markers. These markers fulfill varying functions in the text. Various approaches have been put forward for the classification of discourse markers (e.g., Fraser, 1990, 1999; Knott \& Sanders, 1998; Sanders, Spooren, \& Noordman, 1992; Schiffrin, 1987). Though, Pragmatic Markers (PMs) are described as linguistic devices that play no part in determining the semantic meaning of a discourse segment but play a significant role in the interpretation of the utterance (Fraser, 2009). PMs are different from Discourse Markers (DMs) in that they do not necessarily connect discourse segments, and they may occur with single utterances (Feng, 2008). However, in some classifications, DMs are considered a type of pragmatic markers. Several studies have examined these markers with respect to diverse sections of RAs (e.g., Jalilifar, 2007a, b, 2008; Stotesbury, 2003; Tan-de Ramos, 2010). These studies investigated the frequency and distribution of discourse-pragmatic elements in different sections including abstract and body of the research articles. They revealed that these markers have crucial roles in the way authors express their message to the reader and establish relationships with the addressee.

Textual association is also manifested by Meta-Discourse Markers (MDMs) which refer to the organization of the discourse itself and to the facets of the relationship between author and reader (Hyland, 2005). Scholars including Vande Kopple (1985), Hyland (2005), and Adel (2006) have proposed frameworks for MDMs. A growing body of literature has investigated MDMs in diverse sections of the RAs (e.g., Abdollahzadeh, 2001, 2003; Atai \& Sadr, 2008; Dahl, 2004; Hyland, 1995, 2004; Jalilifar \& Kabezadeh, 2012; Mirshamsi \& Allami, 2013; Rahimpour, 2006; Sultan, 2011; Vassileva, 2001). Sul$\tan$ (2011), for example, examined the use of MDMs in English and Arabic RAs within the field of linguistics and found that transitions and hedges had the highest frequencies in both English and Arabic RAs. Similarly, Jalilifar and Kabezadeh (2012) explored the use of MDMs in introduction and method sections of applied linguistic RAs and showed that transitions were used more than the other MDMs. 
Metaphorical Markers (MMs), as another set of rhetorical markers, are expressions which occur "in the environment of a metaphor's vehicle term, or a unit of discourse that unconventionally refers to, or colligates with the topic of a metaphor on the basis of similarity, matching or analogy" (Goatly, 1997, p. 17). Few studies have analysed MMs in RAs, including Skorczynska and Deignan (2006) and Khany and Rostami (2011). For instance, Khany and Rostami (2011) indicated that the international journals had a more frequent number of MDMs than the Iranian journals, although both types of journals used them similarly.

Metaphorical markers also include attention to modality. Much of the literature on modality (Lyons, 1977; Palmer, 1986; Perkins, 1983) often assumes that the major function of modals is to reveal writer's the state of mind, to indicate that he/she is uncertain, uncommitted, or tentative about the truth value of the proposition. In case of research on modality markers in RAs, very few studies have been reported. For instance, Vold (2006) investigated the use of epistemic modality markers as an important type of hedges - in RAs in three languages and different disciplines. He identified interesting differences between disciplines regarding the type of markers used.

Other rhetorical markers have been suggested and studied in the past research, including author presence markers (e.g., this author, we), intensity markers (e.g., certainly, highly), politeness markers (more or less, briefly), and indirectness markers (e.g., almost, sort of).

Author Presence Markers (APMs) embody expressions by which writers convey their attitudes, feelings, judgments, opinions, and commitments toward the propositional content. An author's influential stance helps him to argue for a position and claim solidarity with the readers, evaluate the other writers' work, and acknowledge alternative views (Hyland, 2004). APMs have been the area of concern in some recent studies (e.g., Crosthwaite, Cheun, \& Jiang, 2017; Harwood, 2005; Hyland, 2002a, b, 2003; Molino, 2010; Sheldon, 2009).

Based on the analysis of some corpora, academic writers use overt authorial identity markers to catch the attention of target readers and highlight their attachment to a certain community of practice (Harwood, 2005; Ivanic, 1998). Several studies have observed the clear presence of the authors' voice in academic writings, such as the use of the first person pronoun combined with an argumentative verb - I/we claim that (e.g., Berge, 2003; Hyland, 1998b; Vassileva, 2000). The review of literature on the existence of first-person pronouns in academic texts has indicated that personal pronouns and possessive adjectives are present in academic writings and that they are well-known as an influential source for building an authorial identity (Kuo, 1999; Tang \& John, 1999). Person markers indicate the author's presence in a text and reflect the importance of this presence in variability in the tenor of a text (Hyland, 1994). Another obvious way researchers opt to demonstrate their identity is referring to their earlier studies through self-citation. Self-citation has been referred to occur in $60 \%$ of all instances of authorial presence markers in a multidisciplinary corpus (Hyland, 2001). Hyland (2001) illustrated that self-reference markers exist more frequently in RAs in the soft disciplines (e.g., Sociology, Philosophy, Applied Linguistics) than the hard ones (e.g., Microbiology, Physics, Engineering). As he elaborated, in hard sciences, academic writers undervalue their individual role and highlight the phenomenon under study instead. Similarly, other self-mention terms like "this author", "the researcher" have been found to be used by some writers especially Ph.D. degree holders (Isik Tas, 2008). 
Intensity markers (IMs) are other affective linguistic devices (Burke, 2011), which encode authors' emotions and dispositions, and are used to negotiate their claims and persuade their readers. These markers reveal the writer's stance towards the presented materials and their communicative function. Intensity markers have lately been studied in different sections of RAs (e.g., Behnam \& Mirzapour, 2012; Beighmohammadi, 2003; Shiri maslaki, 2007). Beighmohammadi (2003), for example, examined the application of IMs across different domains in the introduction section of RAs. He identified more frequent use of intensity markers in RAs in social sciences. Shiri maslaki (2007) also examined abstract sections of research articles in Biology and TEFL and found no significant difference between them in terms of frequency of use of emphatics but found more amplifiers and downtoners in biology articles. Behnam and Mirzapour (2012) focusing on abstract and conclusion sections indicated that the overall distribution of IMs in Applied Linguistics RAs is higher than Electrical Engineering ones.

Lastly, other prominent set of markers include indirectness markers. Brown and Levinson (1987) offer an inclusive definition of indirectness as a set of politeness strategies with the goal of reducing imposition on the addressee bringing about solidarity between the addresser and the addressee. These markers have a lot in common with indirectness markers. Also, politeness markers have similarities with author presence markers and intensity markers. Thus, this article does not elaborate on politeness markers as a separate set of markers in academic writing. Some studies have been conducted on the use of indirectness markers in academic writing (e.g., Alijanian \& Vahid Dastjerdi, 2012; Hinkel, 1997; Leech, 2006; Myers, 2004; Scollon \& Scollon, 1995; Wong, 1990). For instance, Wong (1990) indicated that through using rhetorical questions, writers can hint about the purpose of their texts and state their idea without a direct expression. Myers (2004) also studied on conditionals and demonstrated that through using conditional tense, the writer can prevent a threat to the face and make solidarity. Leech (2006) also revealed that hedges decrease the enforcement of ideas and make the situation smooth for offering author's claim.

Having reviewed the varying rhetorical markers in the literature, it can be deduced that the knowledge of rhetorical markers can highly benefit language users in general and EAP researchers in specific in proper encoding and decoding textual meaning.

\section{The significance of RMs competence for EAP researchers}

In an EAP program, skills required for a learner to perform well in an English speaking academic context across some particular subject areas are instructed usually in a university setting. Developing academic writing abilities is an important goal in these programs. Learning to write academic texts in English is becoming an increasingly important issue for research on L2 writing as well as curriculum design of English for Academic Purposes (Ruan, 2017). The value and importance of writing and publishing an RA in a scholarly journal while or after the completion of an EAP program have been added to the significance of developing EAP writing skills.

Due to the recognized importance of reporting and publishing academic articles, some recent studies have considered the difficulties faced by non-native writers in writing academic research articles (e.g., Derntl, 2014; Flowerdew, 2001; Tahririan \& Jalilifar, 2004; Wette, 2017). These studies highlighted that problems in getting published might 
arise due to some deviations of the international standards in non-native RAs regarding form and structure. Besides, when the instruction on academic writing is required, research in EAP argues for the need to focus on discursive practice (e.g., Charles, 2007; Flowerdew, 1998; Hood, 2004, Hood, 2006; Pho, 2008). Therefore, this study can be of significance to EAP researchers who study English in different academic fields of study and may find difficulty writing a cohesive and coherent research article. In other words, RMs competence in EAP RA writing is essential to the learners' successful handling of scholarly writing tasks encountered in a higher-education setting. Furthermore, this competence is a prerequisite for their entry into the academic discourse community if they decide to pursue scholarship beyond an undergraduate education (Flowerdew, 2000).

\section{Lack of a reductive model of RMs in academic RA writing}

The review of existing models of rhetorical markers reveals that although too much attention has been paid to discursive relations and markers in the past research, not an abridged and decreased model has yet been established. However, the still growing and accumulating research interest in discursive markers in academic writing necessitates a research synthesis that systematically summarizes all the discursive markers for the purpose of writing academic research articles. Thus, the present study raises research attention on RMs in EAP RAs and aims to identify an aggregated network of markers amenable in various sections of research articles. Also, no meta-synthesis has been conducted related to disparate number of models for different rhetorical relations to guide the writers in a more systematic way. Accordingly, this study aims to propose a more reductive model which synthesizes all the markers in different models into one model and can be a common frame of reference for a wide range of EAP disciplines.

\section{Research question}

In specific, the current study addresses the following research question:

- What are the key components (major areas, parameters, and features) of a conceptual model of academic RA Rhetorical Markers Competence model?

\section{Methodology}

Following the qualitative paradigm and in line with the goal of the study, a 'qualitative meta-synthesis' (Walsh \& Downe, 2005) approach was adopted as the research method. The term 'qualitative meta-synthesis' was coined by Stern and Harris (1985) and is known to be an appropriate interpretive method designed to generate a common frame of reference based on qualitative evidence. The strategy of synthesizing integrates the results of studies across both time and researchers.

All the existing models of discursive markers were located through an electronic search in the literature, and the markers in these models were compared, contrasted, and synthesized. Walsh and Downe (2005) proposed a seven step approach for qualitative meta-synthesis: (1) framing a meta-synthesis exercise, (2) identifying relevant papers, (3) deciding what to include, (4) appraising studies, (5) comparing and contrasting exercise, (6) reciprocating translation, and (7) synthesizing translation. 


\section{Framing a meta-synthesis exercise}

In this stage, identifying an appropriate research interest frames the meta-synthesis exercise. The question in this study dealt with interrogating the underpinning themes and concepts in the different models of rhetorical markers which were available in the literature and producing a common conceptual framework for academic RA writers. This stage involved mapping research evidence relevant to the RMs and prioritizing key models and theories for further investigation.

\section{Locating relevant studies, deciding what to include, and appraising studies}

This stage involved a literature search in order to locate topically relevant studies through an electronic search and gather all the possible sources in the available databases. This stage involved an exhaustive electronic search in order to locate topically relevant studies and collect all the possible sources in the search source indexes and databases. Walsh and Downe (2006) suggested a systematic review of trials which requests researchers to locate all related studies. A list of credible journals were also examined to identify related studies, namely Second language writing, English for academic purposes, English for specific purposes, Written Communication, TESOL Quarterly, Pragmatics, Applied linguistics, Language Awareness, Asian ESP journal, System, Modern Language Journal, Text, Discourse studies, Journal of Technical Writing and Communication, Reading and Writing, Functions of language.

The initial effort to choose relevant studies to the research interest produced 385 abstracts and 321 research papers. In result, those studies which could inform the conceptual model of RMs competence were put under more scrutiny.

At this stage, a 'berry picking' procedure (Bates, 1989) was applied. In order to locate the available markers and their relevant models, citation analysis was conducted undertaking a search for the original models in the articles' citations. This stage also helped to find more relevant studies through a recursive web search of citations using Google and Google Scholar. Besides, in case of different models for one specific type of marker, the recency, comprehensibility, applicability in academic RAs, and inclusiveness of the models were taken into consideration. Afterwards, in the appraisal step, studies were investigated based on sample quality criteria (Atkins et al., 2008) and low quality studies were screened out to increase the rigor of meta-synthesis process.

According to Atkins et al. (2008), sample quality criteria are as follow:

- The study is qualitative;

- Research questions are clearly stated;

- Approach is appropriate for the research question;

- Qualitative approach is justified;

- Study context is described;

- Role of the researcher is described;

- Sampling method is described;

- Sampling method is appropriate to the research question;

- Data collection method is described;

- Data collection method is appropriate to the research question;

- Method of analysis is clearly described; 
- Analysis is appropriate for the research question; and Claims are supported by sufficient evidence.

Finally, twenty three articles were selected and accumulated for final meta-synthesis. Thus, this study applied purposive sampling to screen relevant studies in line with the research objectives. Table 1 presents the number of screened and selected references, abstracts, articles, and studies for meta-synthesis.

\section{Comparing and contrasting exercise}

This step aimed to determine how models were similar or different from each other. In so doing, different markers in the models were compared and contrasted through an in-depth reading of the models and exploring their key concepts. Some of the studies seemed to build upon previous models or use borrowed elements from other models, while some were not dependent on other models and seemed to be self-sufficient. The juxtaposition of studies in this way shows the homogeneity and heterogeneity of models (see Table 2). The studies have been ordered with regard to the relevant rhetorical markers in focus.

\section{Reciprocal translation}

In this step, key concepts and themes in each study were identified through a thematic coding strategy. Doing this, overarching core categories (super-themes), subcategories (themes), and codes were obtained using a reciprocal translation process. This process is called reciprocal translation (Noblit \& Hare, 1988) in the sense that inductive and interpretive emergence of concepts and metaphors is done though an iterative categorization of codes and themes. As Noblit and Hare (1988) suggested, in order to combine the relevant studies, a list of themes should be created, and then connections should be established among the relevant themes. As Grounded Theory (Strauss \& Corbin, 1990) has been suggested as an approach for synthesizing data (Barnett-Page \& Thomas, 2009), this approach was adopted as the most appropriate and applicable approach in this study. As recommended by Miles and Huberman (1994), a priori list of codes and categories was prepared based on theoretical background of the study. Each study was examined and classified into a pre-specified category. Our initial categories included (a) discourse markers, (b) pragmatic markers, (c) meta-discourse markers, (d) metaphorical markers, (e) author presence markers, (f) intensity markers, and (g) indirectness markers. We then engaged the stages of Grounded Theory common to original research in qualitative studies. In so doing, key codes and concepts in each study were identified and synthesized following the scheme of grounded theory including the steps of open coding, axial coding, and selective coding. In the open coding procedure, the obtained codes were written verbatim to facilitate the coding and counting process and

Table 1 Number of Screened and Included Materials

\begin{tabular}{ll}
\hline Materials & Number \\
\hline Total abstracts screened & 385 \\
Total full papers screened & 321 \\
Total studies for final inclusion & 23 \\
\hline
\end{tabular}


Table 2 A Comparison of Studies in terms of Focused Rhetorical Markers

\begin{tabular}{|c|c|c|c|c|c|c|c|c|}
\hline N & Author & $\begin{array}{l}\text { Discourse } \\
\text { markers }\end{array}$ & $\begin{array}{l}\text { Pragmatic } \\
\text { markers }\end{array}$ & $\begin{array}{l}\text { Meta- } \\
\text { discourse } \\
\text { markers }\end{array}$ & $\begin{array}{l}\text { Metaphorical } \\
\text { markers }\end{array}$ & $\begin{array}{l}\text { Author } \\
\text { presence } \\
\text { markers }\end{array}$ & $\begin{array}{l}\text { Intensity } \\
\text { markers }\end{array}$ & $\begin{array}{l}\text { Indirectness } \\
\text { markers }\end{array}$ \\
\hline 1 & Fraser (1990) & * & & & & & & \\
\hline 2 & Sanders et al. (1992) & * & & & & & & \\
\hline 3 & Knott \& Sanders (1998) & * & & & & & & \\
\hline 4 & Fraser (1999) & * & & & & & & \\
\hline 5 & Fraser (2005) & * & & & & & & \\
\hline 6 & Fung \& Carter (2007) & * & & & & & & \\
\hline 7 & Fraser (1996) & & * & & & & & \\
\hline 8 & Fraser (1997) & & * & & & & & \\
\hline 9 & Fraser (2009) & & * & & & & & \\
\hline 10 & Erman (2001) & & * & & & & & \\
\hline 11 & Gonzales (2005) & & * & & & & & \\
\hline 12 & Feng (2008) & & * & & & & & \\
\hline 13 & Vande Kopple (1985) & & & * & & & & \\
\hline 14 & Crismore et al. (1993) & & & * & & & * & \\
\hline 15 & Halliday (1994) & & & * & & & & \\
\hline 16 & Hyland (2005) & & & * & & & & \\
\hline 17 & Adel (2006) & & & * & & & & \\
\hline 18 & Goatly (1997) & & & & * & & & \\
\hline 19 & Vassileva (2000) & & & & & * & & \\
\hline 20 & Molino (2010) & & & & & * & & \\
\hline 21 & Quirk et al. (1985) & & & & & & * & \\
\hline 22 & Brown \& Levinson (1987) & & & & & & & * \\
\hline 23 & Myers (2004) & & & & & & & * \\
\hline
\end{tabular}

comparing the main themes of the studies. The codes in the aggregated studies were classified into the initial categories. In the phase of axial coding, all the interlinked categories and codes were then transformed into descriptive themes. The codes that were irrelevant to the main categories were eliminated, and the codes with similar meanings were aggregated under one code.

\section{Synthesis of translation}

This last step of qualitative meta-synthesis involved synthesizing the translated, reconsolidated, and juxtaposed themes and concepts to obtain the overarching theories and components. To wit, a general interpretation of the phenomena was proposed as grounded in the codes and categories of the underlying models.

\section{Results and discussions}

After the recursive search in the literature, twenty three studies relevant to different rhetorical markers were qualitatively met-synthesized using the above-mentioned procedures. As a result, three distinctive core categories of markers were identified as listed in Table 3. A subsequent reading of many articles confirmed the use of these concepts for the analysis of markers in different sections of RA corpora. Applying grounded theory 
Table 3 Frequency of Obtained Codes and Concepts

\begin{tabular}{lll}
\hline Core category & Frequency of concepts & Frequency of codes \\
\hline Pragmatic markers & 4 & 94 \\
Met-discourse markers & 4 & 92 \\
Metaphorical markers & 3 & 22 \\
Total & 11 & 208 \\
\hline
\end{tabular}

(Strauss \& Corbin, 1998) for synthesizing the data set followed the steps of open coding, axial coding, and selective coding. The procedure of thematic categorization of the evidence led to three core categories. Table 3 represents the frequency of codes and concepts for the main dimensions of the synthesized model.

As follows, the synthesized model is described in detail following an explanation of main components of the aggregated models and a comparison of different models of RMs.

\section{Pragmatic markers}

This is the first core category obtained through the qualitative meta-synthesis extracted from the synthesis of 94 codes and four concepts. This core category consists of two subcategories of discourse markers and pragmatic markers. Various classifications of discourse and pragmatic markers are compared and contrasted as follows.

Sanders et al. (1992) and Knott and sanders (1998) argued that all coherence relations have some structures in common: basic operation (They have either a causal or additive nature.); source of coherence (They have coherence on either pragmatic or semantic grounds.); polarity (They link the content either negatively or positively.); order of segments (They have either a basic order or a non-basic order). These features generate 12 classes of coherence markers.

Fraser (1990, 1996, 1997, 1999, 2005, 2009) has also posited various classifications of discourse and pragmatic markers. Fraser (1990), for example, categorized DMs as adverbials (now, then), literally used phrases (to repeat, similarly) idiomatic phrases (all in all, still and all), verbs (look, see), interjections (well), coordinate conjunctions (and, but), subordinate conjunctions (while, however), and terms such as anyway and OK, which don't fall into any of the slots. Fraser (1999) categorized DMs into two major types, including discourse markers which relate messages (contrastive, collateral, inferential, additional markers) and DMs which relate topics (e.g., by the way, back to my point). Similarly, Fraser's (2005) categorization of DMs involved four types: Contrastive (markers showing relations of opposition); elaborative (markers signaling that the current sentence includes an elaboration or explanation of an earlier utterance); inferential (markers signaling that the current utterance conveys a message that is the outcome of some aspect of the previous utterance); and temporal (markers signaling time relations) discourse markers. Fung and Carter (2007) also categorized a core functional paradigm of DMs, namely interpersonal (markers showing relations between interlocutors), referential (markers showing relations between discourse segments, structural (markers signaling topic shift and development) and cognitive (markers denoting thinking processes) dimensions.

Fraser (1996) classified pragmatic markers in four subtypes: basic markers (markers signaling the force of the basic message); commentary markers (markers commenting 
on some aspect of the basic message); parallel markers (markers signaling an entire message in addition to the basic message); discourse markers (expressions marking the relationship between the messages). Then, Fraser (1997) provided a categorization of commentary markers, including assessment, manner of speaking, evidential, perlocutionary, mitigation, and emphasis markers. Erman (2001) recognized three domains for pragmatic markers: Textual-monitors, social monitors, and meta-linguistic monitors. Text-monitors include discourse markers, and editing markers. Editing markers in turn included repair and hesitation markers. Social monitors also involve Interactive markers and comprehension securing markers. Metalinguistic monitors include approximators, hedges, emphasisers.

Gonzalez (2005) categorized pragmatic markers into three structures of rhetorical, sequential, and inferential. Rhetorical discourse structures include comment, clarifier, concluding, emphasizer, evaluator, evidential, addition, delayer, resumption, and topic shifter markers. Sequential structures are divided into three categories: closing segment boundary, development of action initiator, and direct speech initiator markers. Finally, inferential structures include contextual constrainer, justification, face threat mitigator, presupposition, text-world's anchorer, and monitoring markers.

Feng (2008), based on the sematic import of the words, classified pragmatic markers as conceptual and non-conceptual marker. Conceptual pragmatic markers were grouped into epistemic (markers indicating the degree of certitude) and evaluative (markers signaling the writer/speaker's attitudes and feelings) sub-types. Non-conceptual pragmatic markers, on the other hand, were grouped into contrastive, elaborative, and inferential markers. Fraser (2009) provided a more inclusive framework of pragmatic markers adding discourse management markers (DMMs) to his previous models. In this framework, DMMs contained discourse structure, topic orientation, and attention markers. He also outlined four basic classes of topic orientation markers, including return to a prior topic, add to or continue with the present topic, digress from the present topic, and introduce a new topic. Attention markers were also subdivided into the markers of topic return, topic change, and topic continuation.

Considering different classifications of discourse and pragmatic markers within the meta-synthesis approach, Fraser's taxonomy (2009) was found to be more comprehensive. Several studies have taken discourse markers as a subset of pragmatic markers (e.g., Feng, 2008; Fraser, 1996, 1999, 2006, 2009). Table 4 illustrates a meta-synthesized taxonomy of pragmatic markers together with examples randomly derived from the Corpus of Research Articles (CRA) (2007) and Corpus of Journal of Articles (2014). The CRA is a large collection of Research Articles collected from 39 disciplines. Also, the CJA is a large collection of articles from 721 high-impact journals in 38 disciplines in Journal Citation Reports (JCR) or in SCImago Journal Rank (SJR).

\section{Meta-discourse markers}

The next super theme, derived from 92 codes and four concepts, contributes to the meta-discourse markers which, in turn, encompass meta-discourse markers, intensity markers, author presence markers, and indirectness markers. Several studies in the literature have proposed classification systems for meta-discourse markers (e.g., Adel, 2006; Crismore et al., 1993; Hyland, 2005; Vande Kopple, 1985). 
Table 4 A Meta-synthesized Framework of Pragmatic Markers

\begin{tabular}{|c|c|c|}
\hline \multicolumn{2}{|l|}{ Categories sub-categories } & \multirow{2}{*}{$\begin{array}{l}\text { An example in the context } \\
\text { Continuity thinking, I agree, is the }\end{array}$} \\
\hline Basic markers & & \\
\hline \multirow[t]{6}{*}{ Commentary markers } & Assessment markers & these methods can be successfully used \\
\hline & Manner of speaking markers & are limited, outdated, and, frankly, incorrect \\
\hline & Evidential markers & $\begin{array}{l}\text { Indeed, between } 1940 \text { and 1963, } 322 \text { dams } \\
\text { were constructed }\end{array}$ \\
\hline & Hearsay markers & $\begin{array}{l}\text { according to their information gathering } \\
\text { strategy }\end{array}$ \\
\hline & Mitigation markers & That may be true, but you still have to \\
\hline & Emphasis markers & Our aim is by no means to provide \\
\hline \multirow[t]{4}{*}{ Discourse markers } & Contrastive markers & $\begin{array}{l}\text { is insignificant ..., whereas other variables } \\
\text { remain significant. }\end{array}$ \\
\hline & Elaborative markers & Moreover, we confirm that \\
\hline & Inferential markers & Therefore, this evaluation study can help \\
\hline & Temporal markers & remain significant after we control for \\
\hline \multirow[t]{3}{*}{ Discourse management markers } & Discourse structure markers & In general, the absolute price changes \\
\hline & Attention markers & We now examine \\
\hline & Topic orientation markers & And, by the way, there is \\
\hline
\end{tabular}

Vande Kopple's (1985) classification for meta-discourse included textual and interpersonal main categories. Textual meta-discourse constituted text connectives, code glosses, validity markers, and narrators. Interpersonal meta-discourse also included illocution markers, attitude markers, and commentaries. Crismore et al. (1993) then provided a revised categorization of meta-discourse, including two major categories of textual and interpersonal. However, textual component was subdivided into textual markers (logical connectives, sequencers, reminders, and topicalizers) and interpretive markers (code glosses, illocution markers, and announcements). The interpersonal aspect was also reorganized into hedges, certainty markers, attributors, attitude markers, and commentary. Hyland (2005) also proposed a models which comprises two major categories, including interactive MDMs, which concern the writer's awareness of and attention to his readers and interactional MDMs, which refer to writer's attempts to make his views more explicit for the readers.

These studies followed Halliday's (1994) tripartite conception of meta-functions which distinguished three functions of ideational, textual, and interpersonal. Yet, Adel (2006) suggested a rather different model in which he made a distinction between two meta-discourse types: meta-text which represents impersonal and text/code oriented aspects and writer-reader interaction which represents reader and participant oriented aspects of the text.

Vande Kopple's model, as the first systematic attempt to introduce a taxonomy of meta-discourse markers, triggered further studies and taxonomies. Hyland's (2005) taxonomy of meta-discourse markers has been found to be more recent, inclusive, and comprehensible building upon previous taxonomies.

The interactional aspect of metadiscourse deals with the way the authors interact with their readers and engage them. Thus, intensity markers (IMs) fulfill interpersonal functions in RAs and can be regarded as metadiscourse markers. According to Quirk et al.' (1985) model of IMs, these markers are classified into three major classes of 
emphasizers, amplifiers, and downtoners. Crismore et al. (1993) also viewed intensity markers are one type of metadiscourses which actualizes interpersonal functions. They also stated that IMs display the communicative value of the discourse and writers' stance toward the proposition.

Besides, Hyland $(2005,2007)$ views interactional meta-discourse categories as markers of authorial stance. Stance is the way writers convey their attitudes, feelings, judgments, opinions, and commitments toward the propositional content. A similar way of looking at authorial stance is proposed by Vassileva (2000) but under the term authorial presence. She recognizes two types of linguistic means of authorial presence realizations: means of direct indication of authorial presence (first person pronouns) and means of indirect indications of presence and/or discourse depersonalization (passive constructions, hedges, the generic form one) (Vassileva, 2000, pp. 47-8). In this scheme, passive constructions and generic form are not mentioned in Hyland's framework. Boosters and attitude markers are also absent in Vassileva's framework. Thus, the proper authorial stance, which is established in academic writing, highly contributes to interpersonal functions of the RA.

Molino (2010) acknowledged that besides personal and impersonal authorial references, author visibility or invisibility may be realized by means of other rhetorical options, such as possessive adjectives (e.g., my) or metonymic expressions functioning as "abstract rhetors" (e.g., this paper). First-person subject pronouns and inflected verbs, on the one hand, and passive constructions are applied when the writers have to highlight or obfuscate their role as authors. These personal and impersonal references are manifested in different discourse functions like announcing goals and arguments, explaining procedures and data, stating results, and referring back to the text.

Due to the thematic commonalities with the interactional aspect of metadiscourse markers, author presence markers are subsumed under interactional MDMs. Also, as intensity markers fulfill interpersonal roles, they can be regarded as interactional MDMs and thus author presence markers. However, as shown in Fig. 1, Vassileva's categories are added to the framework to make it more comprehensive.

Also, indirectness markers have been found to have features in common with meta-discourse markers. Brown and Levinson (1987) posited a taxonomy of indirectness markers and divided them into three major categories: (A) Rhetorical strategies and markers: devices in this category have a persuasive objective. (B) Lexical and referential markers: indirectness items in this category rely both on meaning and relationships to present a claim. (C) Syntactic markers and structures: these tools manifest indirectness in the sentence structures (Brown \& Levinson, 1987).

Interactional meta-discourse markers

Author Presence Markers

\section{Intensity markers}

\begin{tabular}{|ll} 
Direct indications of presence & First person pronouns \\
\hline $\begin{array}{c}\text { indirect indications of } \\
\text { depersonlization }\end{array}$ & Passive constructions \\
\cline { 2 - 2 }
\end{tabular}

Fig. 1 A Synthesized Typology of Author Presence Markers 
This framework has been applied as a framework of analysis in several studies (e.g., Hinkel, 1997). Myers (2004) also considered hedges, denials, impersonal constructions, and other markers of indirectness as vital strategies to maintain politeness in written academic discourse.

All in all, Table 5 demonstrates a synthesized model of the meta-discourse markers, including the constituent core categories, categories, and subcategories, together with examples in the context collected from Corpus of Research Articles (2007) and Corpus of Journal of Articles (2014). This model incorporates all the elements in the previous models and can account for all types of meta-discourse markers in academic RAs.

\section{Metaphorical markers}

A third type of rhetorical markers suggested by the meta-synthesis includes metaphorical markers. This super-theme was obtained from the synthesis of three concepts and 22 codes.

Based on Goatly's (1997) model of metaphorical markers, MMs involve eighteen types of markers distinguished in three types of factive, non-factive, and counterfactive based on the criterion of factivity (degree of certainty and definiteness). Counterfactives with the strongest effects on the metaphors turn them into literal comparisons.

Furthermore, modality plays a significant role in metaphorical markers, especially in factive and counter-factive structures. The concepts of modality and hedges also overlap to a lesser or greater extent. This connection is very clear in the case of modal verbs. Examples of modality markers are subjunctive mood, modal auxiliary verbs, modal adjectives, modal adverbs, the modal infinitive, etc. They influence the factual status of a sentence in the real world and transform its validity.

A consideration of the very rare number of models on metaphorical markers, Goatly (1997) was identified as the most readily available and inclusive framework of MMs. Table 6 details Goatly's framework together with examples derived from the context of EAP research articles.

\section{A model of RMs competence in writing academic RAs}

The research question in this study interrogated the key components of a new model of RMs in writing academic RAs. To this end, a meta-synthesis approach was adopted as the basis for construct definition of the model. The underpinning rhetorical markers were identified and extracted via semantic analysis. A resulting common frame of reference for RA writers can be illustrated as a new scheme (see Table 7). This framework involves all the principal components of RMs competence in producing scholarly research papers.

\section{Discussions and conclusions}

The competency for producing an academic research article requires specific writing skills different from the regular writing classes (Connors, 1982). Different RA moves and sections fulfill some crucial rhetorical functions. However, RA writers are not sufficiently capable of constructing the appropriate rhetorical devices and connections whose right application boosts the functional establishment of various RA sections. 
Table 5 Meta-discourse Markers Based on Meta-synthesis

\begin{tabular}{|c|c|c|c|}
\hline Concepts & Categories & Subcategories & Examples in the context \\
\hline \multirow[t]{10}{*}{ Meta-discourse markers } & \multirow[t]{5}{*}{ Interactive markers } & Transitions & Thus, for a network of \\
\hline & & Frame markers & The next step was to determine \\
\hline & & Endophoric markers & is quite simple (see Fig. 12). \\
\hline & & Evidentials & as cited in Carruthers 2002 \\
\hline & & Code glosses & Namely, if a child is treated \\
\hline & \multirow[t]{5}{*}{ Interactional Markers } & Hedges & One might want to search \\
\hline & & Boosters & In fact, any neural network that \\
\hline & & Attitude markers & $\begin{array}{l}\text { Unfortunately, data limitations } \\
\text { preclude }\end{array}$ \\
\hline & & Self-mentions & I suggest that \\
\hline & & Engagement markers & Note that due to the appearance \\
\hline \multirow[t]{3}{*}{ Author-presence markers } & $\begin{array}{l}\text { Direct indications } \\
\text { of presence }\end{array}$ & First person pronouns & We found that \\
\hline & \multirow{2}{*}{$\begin{array}{l}\text { Indirect indications } \\
\text { of presence }\end{array}$} & Passive constructions & The study was conducted \\
\hline & & Generic form one & One can find that \\
\hline \multirow[t]{14}{*}{ Indirectness markers } & \multirow[t]{4}{*}{$\begin{array}{l}\text { Rhetorical markers } \\
\text { and strategies }\end{array}$} & Rhetorical questions & $\begin{array}{l}\text { What does it mean to "be } \\
\text { there?" }\end{array}$ \\
\hline & & Tag questions & That's quite a lot, isn't it? \\
\hline & & Disclaimers and denials & $\begin{array}{l}\text { although in no way a } \\
\text { definitive test }\end{array}$ \\
\hline & & $\begin{array}{l}\text { Vagueness and ambiguity } \\
\text { markers }\end{array}$ & $\begin{array}{l}\text { around } 0.1-0.2 \mathrm{~K} \text { in the } \\
\text { modern period }\end{array}$ \\
\hline & \multirow[t]{7}{*}{$\begin{array}{l}\text { Lexical and } \\
\text { referential markers }\end{array}$} & $\begin{array}{l}\text { Hedges and hedging } \\
\text { devices }\end{array}$ & This maybe attributes that \\
\hline & & Point of view distancing & As such, I believe it is important \\
\hline & & Downtoners & $\begin{array}{l}\text { became acceptable partly } \\
\text { because }\end{array}$ \\
\hline & & Diminutives & $\begin{array}{l}\text { because virtually all (97) of } \\
\text { survey respondents }\end{array}$ \\
\hline & & $\begin{array}{l}\text { demonstratives, indefinite } \\
\text { pronouns and determiners }\end{array}$ & that someone can design \\
\hline & & discourse particles & will remain unknown. Anyway \\
\hline & & understatement markers & are fairly easily observable \\
\hline & \multirow{3}{*}{$\begin{array}{l}\text { Syntactic markers } \\
\text { and structures }\end{array}$} & Passive voice & Our study was not designed to \\
\hline & & Nominalization & The decision to develop \\
\hline & & Conditional tenses & If the model fit improves \\
\hline \multirow[t]{7}{*}{ Intensity markers } & Emphasizers & & is certainly the best way \\
\hline & \multirow[t]{2}{*}{ Amplifiers } & Maximizers & is perfectly transparent \\
\hline & & Boosters & with a severely limited picture \\
\hline & \multirow[t]{4}{*}{ Downtoners } & Approximators & to the nearly uniform field \\
\hline & & Compromisers & sort of reflexive thought process \\
\hline & & Diminishers & were only partially compressive \\
\hline & & Minimizers & could scarcely be more dissimilar \\
\hline
\end{tabular}

The present research, offering the compartments of the RMs competence of writing academic RAs in a new model, helps the students in higher education that today experience increasing difficulties in publishing scholarly RAs. Earlier studies have applied 
Table 6 Goatly's (1997) framework of metaphorical markers

\begin{tabular}{lll}
\hline Concepts & Categories & Examples in the context \\
\hline Factives & Intensifiers & results of the analysis are fully reported \\
& Modals & quality should be a certain standard \\
Non-factives & One might think intuitively \\
& Clausal and precision similes & it seems as if, constrained by \\
& Perceptual and cognitive process terms & We regard anxiety as \\
& Medium level modals of possibility & There is a high possibility that \\
Super-ordinate terms & it's kind of an equality thing \\
& Explicit markers & have often been used metaphorically \\
& Copular similes & typically functions as a disinhibitor \\
& Conditionals & empirical research could determine \\
& Negative modals & new entrants could not compete \\
& Mimetic terms & to do with creating a likeness \\
& Misperception terms & create the illusion of depth \\
& Hedges and downtoners & that in almost all cases \\
\hline
\end{tabular}

different models of RMs in different sections of research papers (e.g., Hinkel, 2003; Jalilifar, 2008; Sznajder, 2005; Vold, 2006; Rahimpour, 2006). However, this model can fill the gap in the literature concerning the lack of a systematically organized theoretical framework in that it synthesizes the currently available markers in one model. It also tends to be applicable in writing every specific section of an RA.

Awareness of diverse models for RMs and their constituents can considerably assist students on courses of English for academic purposes if they are to pursue scholarship beyond their undergraduate education (Flowerdew, 2000) and succeed in their academic endeavors. Furthermore, this can highly yield an implication for novice native or

Table 7 A Meta-synthesized Model of RMs Competence in Writing EAP RAs

\begin{tabular}{|c|c|c|}
\hline Dimensions & Concepts & Description \\
\hline \multirow[t]{4}{*}{ Pragmatic markers } & Basic markers & Markers which signal the force of the basic message. \\
\hline & Commentary markers & $\begin{array}{l}\text { Markers which comment and convey attitudes on some } \\
\text { aspect of the basic message. }\end{array}$ \\
\hline & Discourse markers & $\begin{array}{l}\text { Markers which show semantic relations between discourse } \\
\text { segments. }\end{array}$ \\
\hline & $\begin{array}{l}\text { Discourse management } \\
\text { markers }\end{array}$ & $\begin{array}{l}\text { Markers which signal a meta-comment on the structure of } \\
\text { the discourse. }\end{array}$ \\
\hline \multirow[t]{4}{*}{ Meta-discourse markers } & Meta-discourse markers & $\begin{array}{l}\text { Markers which refer to the organization of the discourse } \\
\text { and to the facets of the relationship between author } \\
\text { and reader. }\end{array}$ \\
\hline & $\begin{array}{l}\text { Author-presence } \\
\text { markers }\end{array}$ & Markers which realize authorial presence in the text. \\
\hline & Intensity markers & Markers which encode authors' dispositions toward the text. \\
\hline & Indirectness markers & $\begin{array}{l}\text { Markers which reduce imposition on the reader and bring } \\
\text { solidarity. }\end{array}$ \\
\hline \multirow[t]{3}{*}{ Metaphorical markers } & Factives & $\begin{array}{l}\text { Markers which signal colligations with the topic of a } \\
\text { metaphor on the basis of similarity, matching or analogy. }\end{array}$ \\
\hline & Non-factives & $\begin{array}{l}\text { Markers which signal the uncertainty of the author towards } \\
\text { the truth value of the proposition. }\end{array}$ \\
\hline & Counter-factives & Markers which show literal comparisons. \\
\hline
\end{tabular}


non-native academic researchers to understand whether they have the knowledge of distinct set of rhetorical relations and their typical markers to develop a readable body of academic discourse. This model of RMs can, also, guide the EAP curriculum developers to plan textbooks, lessons, or any other instructional materials dedicated to rhetorical relations and markers in writing academic RAs.

Moreover, such a model can have a constructive role in EAP instruction. This suggests the significance of markers in academic writing and the need of teaching these markers and their rhetorical relations in EAP writing classes. However, a consideration of current writing classes reveals that teaching rhetorical relations and markers are neglected or less concentrated than spelling mistakes, grammar, or writing style in teaching academic writing. EAP instructors seldom take rhetorical markers seriously when they teach academic writing. This results in the lack of coherence and cohesion in students' writing. Accordingly, university instructors can highly benefit from incorporating the components of the model in their syllabus to help the EAP students throughout different research writing courses.

However, it is worth noting here that the new model is not a prescriptive approach to academic writing, and the authors are recommended to find their own way to establish their voice and agency using their own choice of markers. As Littlewood (1996) has noted, an important task in teaching academic EFL writing is to introduce the students to the conventions of academic discourse, while enabling them to self-express in writing.

The current study raises some topics reserved for further work. Future studies which emphasize different categories of RMs and their manifestations are recommended which are specific to distinct academic fields. Additional research can be undertaken to analyze the frequency, range, and distribution of markers in different sections of research articles and in any specific academic discipline. Besides, a cross-linguistic comparison of different rhetorical relations and their markers in academic writing may underline some discrepancies, which can guide native and non-native writers of English to produce a more acceptable research paper.

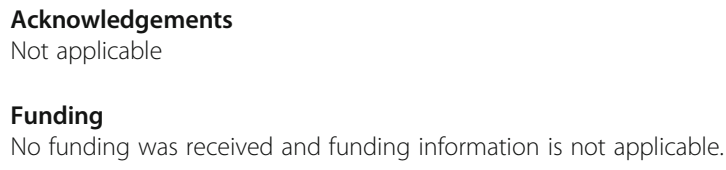

Authors' contributions

RK contributed to the choice of models, examined the meta-synthesized data and worked on the method of methasynthesis. SM selected, coded, and meta-synthesized the relevant studies and was a major contributor in writing the manuscript. MA read and approved the final manuscript. All the authors read and revised the manuscript.

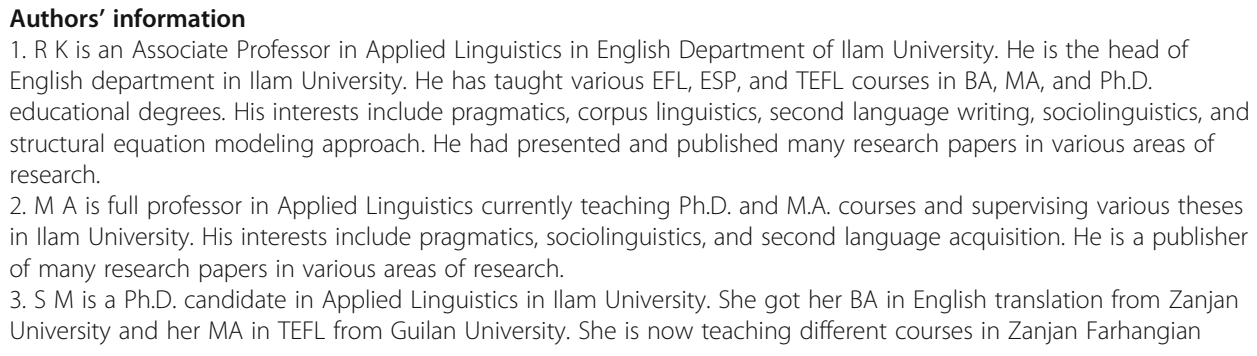


University. She is also an EFL teacher in Education Office. She is interested in the areas of corpus analysis, discourse analysis, sociolinguistics, second language acquisition, academic writing and publishing, and pragmatics. She has conducted different studies in related areas.

\section{Competing interests}

The authors declare that they have no competing interests.

\section{Publisher's Note}

Springer Nature remains neutral with regard to jurisdictional claims in published maps and institutional affiliations.

\section{Author details}

${ }^{1}$ English Department of Ilam University, Ilam, Iran. ${ }^{2}$ llam University, Ilam, Iran.

Received: 2 August 2018 Accepted: 16 December 2018

Published online: 16 January 2019

\section{References}

Abdollahzadeh, E. (2001). Native and non-native writer's use of textual metadiscourse in ELT papers. In Unpublished master thesis. Tehran: University of Tehran.

Abdollahzadeh, E. (2003). Interpersonal metadiscourse in ELT papers by Iranian and Angelo-American academic writers. Paper Presented at International Conference on Multiculturalism in ELT Practice at Basket University.

Adel, A. (2006). Metadiscourse in L1 and L2 English. Philadelphia: John Benjamins.

Alijanian, E., \& Vahid Dastjerdi, H. (2012). The use of indirectness devices in Persian and English argumentative written discourse: A cross-cultural perspective. International Journal of Linguistics, 4(3), 60-70.

Anderson, G. (2001). Pragmatic markers and sociolinguistic variation. US: John Benjamins Publication Corporation.

Atai, M. R., \& Sadr, L. (2008). A cross-cultural study of hedging devices in discussion section of applied linguistics research articles. Teaching English Language and Literature Society of Iran (TELLSI), 2(7), 1-2.

Atkins, S., Lewin, S., Smith, H., Engel, M., Fretheim, A., \& Volmink, J. (2008). Conducting a meta-ethnography of qualitative literature: Lessons learnt. BMC Medical Research Methodology, 8(21).

Barnett-Page, E., \& Thomas, J. (2009). Methods for the synthesis of qualitative research: A critical review. BMC Medical Research Methodology, 9 (59). Available at: http://www.biomedcentral.com/1471-2288/9/59.

Bates, M. (1989). The design of browsing and berrypicking techniques for on-line search interface. Online Review, 13(5), 25.

Behnam, B., \& Mirzaour, F. (2012). A comparative study of intensity markers in Engineering and Applied Linguistics. English language teaching, 5 (7), 158-163.

Beighmohammadi, A. (2003). An investigation into the patterns of use of discourse features of intensity markers in academic research articles of hard science, social science and TEFL. In Unpublished master's thesis. Tehran: University of Tehran.

Berge, K. L. (2003). The scientific text genres as social actions: Text theoretical reflections on the relations between context and text in scientific writing. In K. Fløttum \& F. Rastier (Eds.), Academic discourse. Multidisciplinary approaches (pp. 141157). Oslo: Novus.

Bolden, G. B. (2009). Implementing incipient actions: The discourse marker 'so' in English conversation. Journal of Pragmatics, $41,974-998$.

Brown, P., \& Levinson, S. (1987). Politeness. Cambridge: Cambridge University Press.

Burke, M. (2011). Literany reading, cognition and emotion. An exploration of the Oceanic mind. London and NewYork; Rutledge publishing. Taylor and Francis.

Charles, M. (2007). Reconciling top-down and bottom-up approaches to graduate writing: Using a corpus to teach rhetorical functions. Journal of English for Academic Purposes., 6(4), 289-302.

Connors, U. (1982). The rise of technical writing instruction in America. Journal of Technical Writing and Communication, 12(4), 329-352.

Corpus of Journal of Articles. (2014). Research center for professional communication in English. In The Hong Kong Polytechnic University.

Corpus of Research Articles. (2007). Research center for professional communication in English. In The Hong Kong Polytechnic University.

Crismore, A., Markkanen, R., \& Steffensen, M. S. (1993). Metadiscourse in persuasive writing: A study of texts written by American and Finish University students. Written Communication, 10(1), 39-71.

Crosthwaite, P., Cheun, L., \& Jiang, F. (2017). Writing with attitude: Stance expression in learner and professional dentistry research reports. English for Specific Purposes, 46, 107-123.

Dahl, T. (2004). Textual metadiscourse in research articles: A marker of national culture or of academic discipline. Journal of Pragmatics, 36(10), 1807-1825.

Derntl, M. (2014). Basics of research paper writing and publishing', Int. J. Technology Enhanced Learning, 6(2), 105-123.

Erman, B. (2001). Pragmatic markers revisited with a focus on you know in adult and adolescent talk. Journal of Pragmatics, 33(99), 1337-1359.

Feng, G. (2008). Pragmatic markers in Chinese. Journal of Pragmatics, 40, 1687-1718.

Flowerdew, J. (2000). Discourse community, legitimate peripheral participation, and the nonnative-English-speaking scholar. TESOL Quarterly, 34(1), 17-150

Flowerdew, J. (2001). Attitudes of journal editors to nonnative speaker contributions. TESOL Quarterly, 35(1), 121-150.

Flowerdew, L. (1998). Corpus linguistic techniques applied to text linguistics. System, 26, 541-552.

Fraser, B. (1990). An approach to discourse markers. Journal of Pragmatics, 14, 383-395.

Fraser, B. (1996). Pragmatic markers. Journal of Pragmatics, 6(2), 167-190.

Fraser, B. (1997). Commentary pragmatic markers in English. Estudios Ingleses de la Universidad Complutense, 5, 115-127.

Fraser, B. (1999). What are discourse markers? Journal of Pragmatics, 31, 931-952. 
Fraser, B. (2005). Towards a theory of discourse markers. Retrieved from: http://people.bu.edu/bfraser/

Fraser, B. (2009). Topic orientation markers. Journal of Pragmatics, 41, 892-898.

Fung, L., \& Carter, R. (2007). Discourse markers and spoken English: Native and learner use in pedagogical settings. Applied Linguistics, 28(3), 410-439.

Goatly, A. (1997). The language of metaphors. London: Routledge.

Gonzalez, M. (2005). Pragmatic markers and discourse coherence relations in English and Catalan oral narrative. Discourse Studies, 7(1), 53-86.

Halliday, M. A. K. (1994). An introduction to functional grammar (2nd ed.). London: Arnold.

Harwood, N. (2005). Nowhere has anyone attempted ... in this article I aim to do just that'. A corpus-based study of selfpromotional / and we in academic writing across four disciplines. Journal of Pragmatics, 37, 1207-1231.

Hinkel, E. (1997). Indirectness in L1 and L2 academic writing. Journal of Pragmatics, 27(3), 360-386.

Hinkel, E. (2003). Adverbial markers and tone in L1 and L2 student's writing. Journal of Pragmatics, 35, 1049-1068.

Hood, S. (2004). Managing attitude in undergraduate academic writing: A focus on the introductions to research reports. In L.

J. Ravelli \& R. A. Ellis (eds.), Analysing academic writing: Contextualized frameworks. Continuum 24-44.

Hood, S. (2006). The persuasive power of prosodies: Radiating values in academic writing. Journal of English for Academic Purposes, 5, 37-49.

Hyland, K. (1994). Hedging in academic writing and EAP textbooks. English for Specific Purposes, 13(3).

Hyland, K. (1995). The author in the text: Hedging in scientific writing. Hong Kong Papers in Linguistics and Language Teaching, 18, 33-42.

Hyland, K. (1998b). Boosting, hedging and the negotiation of academic knowledge. Text, 18(3), 349-382.

Hyland, K. (2001). Humble servants of the discipline? Self-mention in research articles. English for Specific Purposes, 20, 207-226.

Hyland, K. (2002a). Authority and invisibility: Authorial identity in academic writing. Journal of Pragmatics, 34, 1091-1112.

Hyland, K. (2002b). Options of identity in academic writing. ELT Journal, 56, 351-358.

Hyland, K. (2003). Self-citation and self-reference: Credibility and promotion in academic publication. Journal of the American Society for Information Science and Technology, 54(3), 251-259.

Hyland, K. (2004). Metadiscourse in academic writing: A reappraisal. London: University of London.

Hyland, K. (2005). Metadiscourse: Exploring interaction in writing. London Continuum.

Hyland, K. (2007). Applying a gloss and reformulating in academic discourse. Applied Linguistics, 28(2), 260-285.

Hyland, K. \& Tse, P. (2005). Evaluative that constructions: Signaling stance in research abstracts. Functions of Language, 12(1), 39-63.

Isik Tas, E. E. (2008). A corpus-based analysis of genre-specific discourse of research: The research article and the PhD thesis in ELT (Unpublished doctoral dissertation). Ankara: Middle East Technical University.

Ivanic, R. (1998). Writing and identity: The discoursal construction of identity in academic writing. Amsterdam: Benjamins.

Jalilifar, A. (2007a). All the way through the hedges: A corpus analysis of hedges in research articles. JAL, 23, 39-63.

Jalilifar, A. (2007b). Hedging as a pragmatic strategy: Variations across disciplines and cultures. TELL, 1(3), 43-69.

Jalilifar, A. (2008). Discourse markers in composition writings: The case of Iranian learners of English as a foreign language. English Language Teaching, 1, 114-122.

Jalilifar, A., \& Kabezadeh, F. (2012). A comparative study of textual metadiscourse markers in introduction and method sections of applied linguistics research articles. Journal of Language, Culture, and Translation (LCT), 1(1), 17-31.

Khany, R., \& Rostami, M. (2011). Metaphor markers in sub-disciplines of applied linguistics research articles: The case of local and international journals. IJALS, 1(3), 34-49.

Khany, R., \& Tazik, K. (2010). A comparative study of introduction and discussion sections of sub-disciplines of applied linguistics research articles. Journal of Applied Language Studies (JALS), 1(2), 97-122.

Knott, A., \& Sanders, T. (1998). The classification of coherence relations and their linguistic markers: An exploration of two languages. Journal of Pragmatics, 30(2), 135-175.

Kuo, C. H. (1999). The use of personal pronouns: Role relationships in scientific journal articles. English for Special Purposes, 18(2), 121-138.

Leech, G. (2006). Politeness: Is there an east-west divide. Journal of Politeness Research, 3(2), 167-206. https://doi.org/10.1515/ PR.2007.009.

Li, L., \& Ge, G. (2009). Genre analysis: Structural and linguistic evolution of the English-medium medical RA (1985-2004). English for Specific Purposes, 28, 93-104.

Littlewood, W. (1996). Academic writing in intercultural contexts: Integrating conventions and personal voice. Hong Kong Journal of Applied Linguistics, 1, 1-18.

Luo, N., \& Hyland, K. (2016). Chinese academics writing for publication: English teachers as text mediators. Second language writing, 33, 43-55.

Lyons, J. (1977). Semantics. Cambridge: Cambridge University Press.

Mann, W. C., \& Thompson, S. A. (1988). Rhetorical structure theory: Toward a functional theory of text organization. Text, 8(3), 243-281.

Miles, M. B., \& Huberman, A. M. (1994). Qualitative data analysis: An expanded sourcebook. Thousand Oaks, CA: Sage.

Mirshamsi, A., \& Allami, H. (2013). Metadiscourse markers in the discussion/conclusion section of Persian and English master's theses. The Journal of Teaching Language Skills, 5(3), 23-40.

Molino, A. (2010). Personal and impersonal authorial references: A contrastive study of English and Italian linguistics research articles. Journal of English for Academic Purposes, 9, 86-101.

Myers, G. (2004). Matters of opinion: Talking about public issues. Public Opinion Quarterly, 70(3), 409-412.

Noblit, G. W., \& Hare, R. D. (1988). Meta-ethnography: synthesizing qualitative studies. Newbury Park: Sage.

Palmer, F. R. (1986). Mood and modality. Cambridge: Cambridge University Press.

Perkins, M. (1983). Modal expressions in English. London: Frances Pinter.

Pho, P. (2008). Research article abstracts in applied linguistics and educational technology: A study of linguistic realizations of rhetorical structure and authorial stance. Discourse Studies, 10, 231-250.

Pitler, E., Raghupathy, M., Mehta, H., Nenkova, A., Lee, A., \& Joshi, A. (2008). Easily identifiable discourse relations. Proceedings of the 22nd International Conference on Computational Linguistics (COLING 2008), Manchester, August. 
Quirk, R., Greenbaum, S., Leech, G., \& Svartvik, J. (1985). A comprehensive grammar of the English language. London: Longman.

Rahimpour, S. (2006). Contrastive rhetoric of English and Persian texts; Metadiscourse in Applied Linguistics research articles. Unpublished Master thesis, University of Mashhad.

Ruan, Z. (2017). Lexical bundles in Chinese undergraduate academic writing at an English Medium University. RELC Journal, 48(3), 327-340.

Sanders, T., Spooren, W., \& Noordman, L. (1992). Toward a taxonomy of coherence relations. Discourse Processes, 15, 1-35.

Schiffrin, D. (1987). Discourse markers. Cambridge: Cambridge University Press.

Scollon, R., \& Scollon, S. W. (1995). Intercultural communication. Oxford: Blackwell.

Sheldon, E. (2009). From one I to another: Discursive construction of self-representation in English and Castilian Spanish research articles. English for Specific Purposes, 28, 251-265. https://doi.org/10.1016/..esp.2009.05.001.

Shiri Maslaki, T. (2007). A comparative study of discoural features in natural sciences and applied linguistics. Unpublished master's thesis, University of Tabriz, Tabriz.

Skorczynska, H., \& Deignan, A. (2006). Readership and purpose in the choice of economics metaphors. Metaphor and Symbol, $21(2), 87-104$.

Stern, P., \& Harris, C. (1985). Women's health and the self-care paradox: A model to guide self-care readiness — Clash between the client and nurse. Health Care for Women International, 6(12).

Stotesbury, H. (2003). Evaluation in research article abstracts in the narrative and hard sciences. Journal of English for Academic Purposes, 2, 327-341.

Strauss, A., \& Corbin, J. (1990). Basics of qualitative research: Grounded theory procedures and techniques. London: Sage.

Strauss, A., \& Corbin, J. (1998). The basics of qualitative research: Techniques and procedures for developing grounded theory. Thousand Oaks, CA: Sage Publications.

Sultan, A. (2011). A contrastive study of met discourse in English and Arabic linguistics research articles. ACTA LINGUISTICA $5(11), 28-41$.

Swales, J. (2004). Research genres. Cambridge: Cambridge University Press.

Sznajder, H. S. (2005). A corpus based description of metaphorical marking patterns in scientific and popular business discourse. English for Specific Purposes, 22, 172-182.

Tahririan, M. H., \& Jalilifar, A. R. (2004). Genre analysis of thesis and dissertation abstracts: Variation across cultures. IJAL, 7(2), $121-143$.

Tan-De Ramos, J. (2010). A comparative study of the discourse marker types in the body section of the research papers of DLSU students. TESOL Journal, 2, 62-73.

Tang, R., \& John, S. (1999). The "I" in identity: Exploring identity in student academic writing through the first person pronoun. English for Specific Purposes, 18(Supplement 1), S23-S39.

Vande Kopple, W. (1985). Some exploratory discourse on Metadiscourse. College Composition and Communication, 36, 82-93.

Vassileva, I. (2000). Who is the author? A comparative analysis of authorial presence in English, German, French, Russian and Bulgarian academic discourse. Sankt Augustin: Asgard Verlag.

Vassileva, I. (2001). Commitment and detachment in English and Bulgarian academic writing. English for Specific Purposes, 20, 83-102.

Vold, T. E. (2006). Epistemic modality markers in research articles: A crosslinguistic and cross-disciplinary study. International Journal of Applied Linguistics, 16(1), 61-87.

Walsh, D., \& Downe, S. (2005). Meta-synthesis method for qualitative research: A literature review. Methodological Issues in Nursing Research, 50(2), 8.

Walsh, D., \& Downe, S. (2006). Appraising the quality of qualitative research. Midwifery, 22(2), 108-119.

Wette, R. (2017). Using mind maps to reveal and develop genre knowledge in a graduate writing course. Journal of Second Language Writing, 38, 58-71.

Wong, H. (1990). The use of rhetorical questions in written argumentative discourse. In L. Bouton \& Y. Kachru (Eds.), Pragmatics and language learning (Vol. 1, pp. 187-208). Urbana-Champaign: University of Illinois.

\section{Submit your manuscript to a SpringerOpen ${ }^{\circ}$ journal and benefit from:}

- Convenient online submission

- Rigorous peer review

- Open access: articles freely available online

- High visibility within the field

- Retaining the copyright to your article

Submit your next manuscript at $\boldsymbol{\nabla}$ springeropen.com 